ORIGINAL ARTICLE

\title{
Pre-employment urine drug testing of hospital employees: future questions and review of current literature
}

\author{
M R Levine, W P Rennie
}

Occup Environ Med 2004;61:318-324. doi: 10.1136/oem.2002.006163

See end of article for authors' affiliations

a.....................

Correspondence to: Assistant Professor M R Levine, Division of Emergency Medicine, 676 North St Clair St, Suite 2125, Chicago, IL 60611, USA; mrlnyc@aol.com

Accepted 28 May 2003
Background: Patient safety and optimisation of worker performance are high current priorities. Arguments over employee drug testing have been debated over the past two decades.

Aims: To review prior information to reveal how current principles and practices regarding preemployment drug testing of health care workers evolved, and to explore pressing current and future issues. Methods: A literature search of Medline from 1980 to 1999 was performed. This yielded seven citations that reported results of pre-employment drug testing of health care workers, which we critically reviewed. Results: The process by which a rational testing process was developed for pre-employment urine drug screening in the health care field is illustrated. Also depicted are some important principles, inequities, and shortcomings of the system. The range of positive tests was wide, from $0.25 \%$ to $12 \%$. Testing was not always applied uniformly to all health care workers. It became apparent that positive tests also require medical review to determine if they were truly due to illicit substance use.

Conclusions: Although pre-employment drug testing programmes in the health care industry have been firmly in place for many years, it is unclear whether such strategies have achieved their stated purposes. The next step is to study whether such programmes are effective at accomplishing specific goals, such as decreasing absenteeism, turnover, accidents, and medical errors, in order to justify continuing preemployment testing versus changing to an alternative testing strategy.
A 1790 statute authorised that every soldier be given a daily ration of a quarter pint of rum, whiskey, or brandy. ${ }^{1}$ Over the subsequent 200 years the tone has shifted to one of concern about the ill effects of alcohol and drugs in the workplace. In the early 1980s, the US military introduced a "zero tolerance" random drug testing policy after an explosion aboard the USS Nimitz in which postmortem examinations showed that half of the crew members who were killed tested positive for marijuana. Over the next eight years, illicit drug use in the military dropped from $30 \%$ to $5 \% .^{2}$ In 1986, President Reagan issued Executive Order 12564 on the Drug Free Federal Workplace, which mandated each executive agency to establish a programme to test for drug use by federal employees in "sensitive" positions. This programme mandates drug testing following accidents, in those for whom there is a reasonable suspicion of use, and for new job applicants. ${ }^{3}$ The Department of Transportation enacted a similar programme in response to a fatal train crash in 1987 in Chase, Maryland in which the driver and brakeman tested positive for marijuana. Except for the transportation and nuclear power industries, no federal laws specifically regulate any private sector drug testing programmes. However, urine drug testing has become a common practice in the American workplace. In fact, more than $90 \%$ of US companies with over 500 employees have some sort of drug screening programme in place. ${ }^{4}$ This trend has extended to include the health care industry, as most health care institutions have a policy for testing their employees. ${ }^{5}$

Unfortunately, the current process that the health care industry uses to police itself for substance abuse is flawed. It is a system lacking clearly explicit goals and is fraught with vague policies that are applied selectively rather than uniformly. The current standard drug screening systems in the health care industry have evolved to please employees, employers, the general public, regulatory bodies, and meet the least legal resistance. The current standards, however, have not been shown to benefit patients. The objective of this paper is to illustrate how we arrived at the current state of drug testing of hospital employees through a review of the current literature that specifically reported data on testing of health care workers, so that areas of future research and refinement can be identified. A review of this topic is timely because after a surge in publication of reviews of drug screening of hospital employees in the mid 1980s to the mid 1990s, original research has dropped off, implying that we are complacent with the current standards. At the same time patient safety has been thrust into the spotlight as a higher priority. Drug testing is a potential area to help optimise worker performance in this high risk environment. Recommendations are offered in order to address some of these weaknesses of the current system. Strengthening and rationalising current policies and procedures are intended to promote patient safety.

\section{Drug abuse in the medical community}

Evidence suggests that health care workers are at increased risk for substance abuse, ${ }^{6}$ perhaps because of the unique exposure to the stressors of death and suffering, ${ }^{78}$ or because of easier access to substances with abuse potential. ${ }^{9-11}$ However, until the 1980s, the prevalence of drug abuse in the medical community was mostly speculative. ${ }^{12}$ Survey data regarding illicit drug use by physicians was first published in the New England Journal of Medicine in 1986. In this study of a random sample of 500 practising physicians, 70\% responded, with $10 \%$ of the responders reporting current drug use at least once a month. Three per cent reported a history of drug dependence. ${ }^{13}$ These results were comparable to the rest of the workforce, according to the 1988 National Household Survey on Drug Abuse, which estimated that about $8 \%$ of full time employed persons have used illicit drugs in the past month. ${ }^{14}$ According to the National Council of State Boards of Nursing, more than one out of three disciplinary cases in nursing is drug related. ${ }^{15}$ Other studies report that the 
Main messages

- It is unclear whether pre-employment hospital employee drug testing positively impacts patient safety or saves hospitals money. The specific goals of such testing should be explicitly stated so that it can be studied whether such programmes accomplish their designed purposes.

prevalence of substance abuse among medical students and residents is similar to the general population. ${ }^{16}{ }^{17}$

\section{Why hospital employees should be tested}

The health care industry, like other industries, has responded to the prevalence of drug use in society by the establishment of a variety of different drug testing programmes. In a 1988 nationwide survey of 183 hospital personnel managers' attitudes towards drug abuse and testing, a majority agreed that because of the nature of health care institutions, these organisations operate under a higher standard of accountability than other organisations. They favoured an involuntary drug testing policy, even for those not directly involved in patient care, admittedly not knowing whether such testing will yield better patient care. ${ }^{18}$ Other reasons cited by hospital personnel managers are improved public relations ${ }^{18}$ and protection from litigation. ${ }^{5}$ 19-21

The rationale behind most testing programmes is the belief that they will promote safety of both co-workers and the general public. ${ }^{522}{ }^{23}$ Testing is also thought to deter drug use, to help identify employees at risk for drug problems, and to enable them to seek assistance. Through minimising the absenteeism and turnover associated with drug abuse, drug testing may lead to increased productivity and lower workplace costs. Ultimately, testing programmes are thought to lead to a safer, drug-free workplace and to higher employee morale and increased public trust. Testing programmes also help institutions meet legal obligations for occupational safety laws. The American Hospital Association's (AHA) policy on drug screening of hospital employees, which was approved in 1992, recommends that health care institutions adopt a policy that includes pre-employment testing, forcause testing, and post-accident testing. ${ }^{24}$ The Drug-Free Workplace Act passed in 1988 includes mention that entities that receive $\$ 25000$ or more in federal grants must provide a drug-free workplace, which compels many hospitals to comply with this legislation. ${ }^{5}$

\section{Why hospital employees should not be tested}

There are also many arguments against employee drug testing. The evidence linking drug use and workplace difficulties is much weaker than initial estimates. ${ }^{25} 26$ Detractors of drug testing cite that there is almost no scientific data that testing is effective in achieving its goals. The monumental task of drug testing, it is argued, is of potentially greater legal and public relations benefit than benefit to patient safety. A rational and evidence based approach is necessary to ensure optimal functioning of care providers. Drug testing is arguably less important than addressing the performance impact of overnight work, circadian rhythm disruption, and overwork.

Testing does not necessarily measure impairment, abuse, or intoxication. The presence of a banned substance does not mean that cognitive impairment is present or clinical performance is impacted. Further, routinely used medicines such as decongestants, antihistamines, stimulants,
Policy implications

- The specific goals of hospital employee drug testing should be explicitly stated. A strategy tailored towards meeting those specific goals should be chosen.

and other prescribed substances can also profoundly impair functioning.

Despite the lack of evidence for the utility of drug testing, the impact is profound. The mere suspicion of use or, worse yet, a false positive test can have a long term, devastating impact on an individual's life and career. Immense administrative, legal, and medical effort would be required to prove innocence once suspected of illicit use.

The process of testing is also intrusive, so evidence of the need is demanded. Specimen collection under direct observation is intrusive and embarrassing. Testing can provide information about medical conditions unrelated to substance abuse, informing the employer of more than should legally be available. Involuntary drug testing has been called an unwarranted invasion of privacy, a form of "chemical McCarthyism", ${ }^{27}$ and a form of social control that influences lifestyle but not work performance.

\section{Testing strategies}

Employers have used several strategies when testing for drugs, in large part guided by the legal ramifications of each. Screening can occur at several different points in time:

(1) During the application process

(2) After a job offer has been extended but before employment begins (pre-employment testing)

(3) Randomly after employment has commenced

(4) After accidents or when an employee behaves in a manner suspicious for substance abuse ("for cause" testing).

Screening prior to being extended a conditional job offer would require applicants to disclose any prescription drugs that they take. This has been interpreted in courtrooms as a violation of the American with Disabilities Act (ADA), ${ }^{28}$ which prohibits "inquiries of a job applicant as to whether such an applicant is an individual with a disability ..." Such inquiries, however, can be sought after a job offer has been made, making pre-employment testing legally acceptable. Employers have indeed met the least legal resistance when using strategies based on "for cause" and pre-employment testing. These two forms of testing pose the least liability to employers, are less expensive than random testing, and are most acceptable to labour unions. For these reasons and not because of efficacy, pre-employment and "for cause" testing are the most prevalent strategies. ${ }^{53}$

Random testing of active employees without suspicion of substance abuse has generated the most resistance and controversy. Such testing has been called a violation of the Fourth Amendment to the Constitution, which prohibits illegal search and seizure without just cause, and has been defeated in court. Random testing is more expensive because it requires a greater frequency of testing to be effective. On the other hand, random screening does not single out individuals for suspicious behaviour or substandard performance. When applied uniformly, everyone has an equal chance of being tested, so individuals selected for testing do not risk being labelled as possible drug users. ${ }^{29}$ The Supreme Court has decided in favour of lower court decisions 
upholding various forms of random drug testing, ${ }^{30-33}$ and some hospitals do practice random drug screening. ${ }^{53} 34$

All things being considered-health and safety, individual rights, the US Constitution and legal system-pre-employment and "for cause" testing have been the paths of least resistance. The literature review in this paper will discuss preemployment testing since it is by far the most prevalent approach with reported data.

\section{STUDY SELECTION}

As the health care industry began to test its employees, there were many questions that arose regarding the implementation, cost effectiveness, and efficacy of testing this population. Data have been published regarding pre-employment urine drug testing of health care workers, which has helped set current standards and reflects the evolution of the preemployment drug testing systems in place in many health care institutions today. A literature search of Medline from 1980 through 1999, limited to the English language but not to a specific country, was performed using different combinations of the keywords: preemployment, pre-employment, urine screen(ing), urine test(ing), drug screen(ing), and drug test(ing). In addition we evaluated the reference section of each paper and reviewed additional references found this way. These searches yielded seven citations which reported results of pre-employment drug testing of health care workers, all of which were from the United States (see table 1). Each study was critically reviewed for data quality, validity, insight, and conclusions.

\section{RESULTS}

\section{Early studies}

The earliest published report of pre-employment urine toxicology screening of health care workers appeared in the medical literature in $1983 .^{35}$ From January to May 1981, 500 consecutive urine toxicology examinations were performed on all "prospective hospital employees". It was unclear whether testing was performed before or after hire. There was no mention of job description or if physicians were included in the study population, but all 500 screens were "consecutive" and "all" prospective employees were included. Subjects were informed just prior to the examination that a urine drug screen would be obtained. Lewy reported that $2.6 \%$ were confirmed positive for Valium, barbiturates, amphetamines, PCP, or opiates. Specimens were not tested for marijuana or alcohol. None of these cases could be predicted based on the medication histories obtained from subjects prior to testing. After follow up and further review, however, all but one of the positive tests could be attributable to legitimate medicinal use. These positive testing subjects were not considered users of illicit substances and continued on to employment. Several of these employees were offended about being recalled. It is notable that the employees failed to give detailed medication histories before drug testing, but were able to give complete histories after being confronted with positive test results. For unknown reasons, people may not wish to disclose some illnesses, may consider certain conditions not significant enough to report, or may not consider recent, intermittent, or temporary prescription medication use as part of their medical history. The one remaining positive case in this study did not provide a legitimate explanation and had displayed a peculiar affect that raised serious clinical suspicion of substance abuse by the screening physician prior to testing, although there is no mention whether this was truly documented prior to testing, or just a retrospective observation. Based on these findings, Lewy suggested that the most rational and cost effective approach to the detection of drug abuse would be a medical examination and subsequent selective testing "for cause" based on the physical examination instead of testing every prospective employee. However, because there is no mention of the examining physicians documenting their pretest suspicion of drug use for each of the subjects, this seems to be an unwarranted conclusion based on the data presented.

In the ensuing years, Lewy seemed to have a change of heart. He published the results of pre-employment urine drug screens of all 791 house staff physicians beginning training at Presbyterian Hospital at the Columbia-Presbyterian Medical Center between 1987 and $1990 .^{36}{ }^{37}$ Subjects were notified in advance (but it was not specified how far in advance) about the drug testing programme. House staff orientation included an explanation of the hospital's drug testing policy and the counselling and treatment services available to them. Positive tests were referred to "an experienced clinician" for further evaluation. Two individuals $(0.25 \%)$ confirmed positive for illegal drugs, one for marijuana, the other for cocaine and marijuana. Both were referred for treatment and were subsequently appointed and began their residencies. Lewy acknowledged that such testing was not an accurate indicator of recent drug use since the house staff received advance notification of testing. However, this time Lewy did not

Table 1 Summary of published results of pre-employment urine drug testing (see text for further details)

\begin{tabular}{|c|c|c|c|c|}
\hline Author(s), year & Subjects & Substances tested & $\%$ positive tests & Comments \\
\hline Lewy, 1993 & $\begin{array}{l}500 \text { "prospective } \\
\text { hospital employees" }\end{array}$ & $\begin{array}{l}\text { bz, barb, amph, } \\
\text { pcp, op, coc }\end{array}$ & 2.6 & $\begin{array}{l}\text { Author suggested such screening is wasteful } \\
\text { since only one positive was non-medicinal. }\end{array}$ \\
\hline $\begin{array}{l}\text { Lewy, 1988, } \\
1991\end{array}$ & 791 housestaff & $\begin{array}{l}\text { bz, barb, amph, } \\
\text { pcp, op, thc, coc }\end{array}$ & 0.25 & $\begin{array}{l}\text { Same author declared testing useful in sending } \\
\text { message about drug use being unacceptable } \\
\text { and providing access to help resources. }\end{array}$ \\
\hline $\begin{array}{l}\text { Smith and } \\
\text { Hanbury, } 1991\end{array}$ & $\begin{array}{l}172 \text { "prospective } \\
\text { employees", no faculty }\end{array}$ & $\begin{array}{l}\text { bz, barb, amph, } \\
\text { pcp, op, thc, meth, coc }\end{array}$ & 4.1 & $\begin{array}{l}\text { Not enough positive tests }{ }^{7} \text { to validly predict } \\
\text { patterns of abuse reported by authors. }\end{array}$ \\
\hline Parish, 1989 & $\begin{array}{l}195 \text { "recently hired } \\
\text { hospital employees" }\end{array}$ & $\begin{array}{l}\text { bz, barb, amph, pcp, op, } \\
\text { thc, coc, pro, mep, phe }\end{array}$ & 12 & $\begin{array}{l}\text { No medical review of positives. No correlation } \\
\text { found between test results and job performance. }\end{array}$ \\
\hline \multirow{4}{*}{$\begin{array}{l}\text { Moore and } \\
\text { Swafford, } 1993 \\
\text { Lange et al, } \\
1994\end{array}$} & 3514 "new employees" & $\begin{array}{l}\text { bz, barb, amph, pcp, op, } \\
\text { thc, meth, coc, pro, etoh }\end{array}$ & $\begin{array}{l}5 \\
2.2 \text { after medical review }\end{array}$ & $\begin{array}{l}\text { Example of importance of medical review of } \\
\text { positive tests. }\end{array}$ \\
\hline & $\begin{array}{l}\text { Prospective hospital } \\
\text { employees (no } \\
\text { medical staff) }\end{array}$ & $\begin{array}{l}\text { bz, barb, amph, pcp, } \\
\text { op, thc, meth, coc }\end{array}$ & $\begin{array}{l}10.8 \text { in } 1989 \text { without } \\
\text { any medical review }\end{array}$ & $\begin{array}{l}\text { Shows the lack of sensitivity of testing "for } \\
\text { cause" only, which was the policy in } 1989 . \\
\text { Implementation of pre-employment testing }\end{array}$ \\
\hline & 593 in 1989 & & $\begin{array}{l}5.8 \text { in } 1991 \text { before } \\
\text { medical review }\end{array}$ & $\begin{array}{l}\text { between } 1989 \text { and } 1991 \text { may have acted as a } \\
\text { deterrent and accounted for the fewer positives }\end{array}$ \\
\hline & 365 in 1991 & & $\begin{array}{l}3.8 \text { in } 1991 \text { after } \\
\text { medical review }\end{array}$ & in 1991. \\
\hline
\end{tabular}

bz, benzodiazepines; barb, barbiturates; amph, amphetamines; pcp, phencyclidine; op, opiates; thc, marijuana; meth, methadone; pro, propoxyphene; mep, meperidine; phe, phenothiazines; etoh, ethanol. 
suggest that indiscriminate pre-employment urine testing was wasteful. Instead he described house staff drug testing as a useful adjunct to the management of drug use among physicians because it provides a clear message that drug use is not condoned. Furthermore, it presents opportunities for the discussion of issues regarding substance abuse, including treatment resources. After all, the decision of an organisation to perform drug screening may not be based solely on the cost effectiveness of testing but also on regulatory requirements, safety concerns, and public image. These issues, according to Lewy, may outweigh the financial drawbacks of such testing.

Smith and Hanbury ${ }^{38}$ studied 172 consecutive prospective employees of a large New York City hospital who were informed several days in advance that urine toxicology screens would be part of their pre-employment physical examinations. One applicant never showed up. Prospective faculty and attendings were excluded since their pre-employment physical examinations were not performed at the Employee Health Service like the other subjects; other MDs and PhDs were included. Screens tested for the presence of opiates, methadone, cocaine, THC, phencyclidine, benzodiazepines, amphetamines, and barbiturates. Seven $(4.1 \%)$ tested positive for non-prescription drugs, either cocaine, marijuana, or both. Smith and Hanbury noted patterns of positive specimens in those of lower socioeconomic status, but positive specimens were not related to gender, age, ethnic identity, or job category. With only seven positive tests, these patterns have little validity. Smith and Hanbury noted that the percentage of positive screens was remarkably similar to those of a 1988 study of 37453 applicants for military service, and concluded that applicants for medical centre positions cannot be assumed to be more immune to the illicit drug use epidemic than the rest of society. This study did not provide any evidence to assume that this blanket statement is applicable to attendings and faculty since they were excluded from the study.

\section{Drug screening and job performance}

A 1989 study by Parish looked for a correlation between urine toxicology examination results and job performance. ${ }^{39}$ Over a six month period all newly hired hospital employees at a large teaching hospital in a moderate sized urban area in Georgia had pre-employment urine screening for barbiturates, opiates, benzodiazepines, propoxyphene, meperidine, THC, amphetamines, cocaine, phencyclidine, and phenothiazines. Prospective employees were notified during the interview process that drug screening would be part of their physical examination and that the results would not have any bearing on their job, and would be used as part of a study of the usefulness of urinary drug testing. One year later, a reviewer who had no access to drug screening results extracted information from personnel folders regarding disciplinary actions, promotions, commendations, absenteeism, job retention, supervisor evaluations, and reasons for termination. This information was forwarded to the author for comparison of these data with the drug test results.

Of the 195 employees screened, 12\% (22) tested positive for drugs, the majority (14), for THC. There were no positive toxicologies for cocaine or heroin. This study could not show a relation between positive pre-employment drug screens and substandard job performance; however, the size of the drug positive group was not large enough to allow valid comparisons. Furthermore, there was no medical review of positive tests to determine which ones could have had medical explanations, so a significant number of the positives may have been users of prescription medications, not illicit substances, but were nevertheless included in the drug user cohort. Parish concluded that hospital money could be better spent on programmes other than drug testing if larger studies that include more variables to detect subtler differences in job performance could reproduce his findings. There is no reason to assume that larger studies would validate Parish's findings; in fact, there is evidence to the contrary in other industries. Larger controlled studies in the US Postal Service involving thousands of employees clearly showed correlations between positive drug tests and increased absenteeism, involuntary turnover, accidents, injuries, and discipline..$^{25} 26$ Unless the health care industry is not as susceptible as the rest of the workforce to the substance abuse epidemic, these adverse correlations would be expected to apply to hospital employees as well.

\section{The importance of medical review}

In 1993, the Journal of Occupational Medicine published results of the largest study population to date of pre-employment urine drug screens in the health care industry. ${ }^{40}$ Moore and Swafford presented one year of pre-employment drug screening results of all 3514 new employees of Samaritan Health Services, a large health care provider which serves the greater Phoenix area and several smaller communities. Interestingly, this was the first such study to include alcohol on its toxicology screen. The other substances screened for were amphetamines, barbiturates, cannabinoids, benzodiazepines, cocaine, methadone, opioids, phencyclidine, and propoxyphene. Subjects were given 24 hours notice prior to testing. A medical review officer (MRO) was assigned to meet with each employee that tested positive to review the results along with the medical history to exclude any legitimate medicinal use of these substances. A total of $5 \%$ of the tests were confirmed positive, but only $2.2 \%$ were determined to be "true" positives after the MRO met with the employee. "False" positives were usually a result of initially unreported prescription medications. Approximately $80 \%$ of "professional" applicants (undefined by the authors) who tested positive did so for prescription drugs, while more than $90 \%$ of ancillary applicants (such as maintenance, housekeeping, and kitchen personnel) who tested positive did so for illicit drugs. The investigators believed that the relatively high numbers of prescription-positive screens could be attributed to the fact that health care workers have easy access to "hallway office visits" and "curb stone consultations". The Samaritan Health Services study was unique in citing other complex scenarios of positive screens during the study and concluded that such drug testing programmes should not be undertaken without MRO involvement to help identify false positive results.

The medical review officer is a position of crucial importance, recognised by the creation of MRO guideline manuals and training courses with certification examinations first offered in the early 1990s. The MRO serves as a person outside the corporate structure who can review the results of testing with the employee confidentially and can assess the circumstances leading to the positive test. The MRO must review positive report documents, notify employees of positive test results, and review medical records, history, and other biomedical factors. The employee is then given the opportunity to discuss the test result, and is examined by the MRO for physical signs of substance abuse. Other responsibilities of the MRO include an understanding of how tests are performed, how specimens are collected, how results should be interpreted, and what courses of action may be taken. The MRO must know the period of time which individual drugs can be detected in urine and be familiar with the concept of cutoffs as used by the laboratory to report the results of their tests. Employees' requests for retesting are processed by the MRO who may authorise testing of a "split specimen" for drug metabolites. The MRO is then responsible for communicating the meaning of the test results to administrative 
officials who may or may not take action against the employee. The MRO's role is basically restricted to interpreting and reviewing positive test results; the MRO is not concerned with false negatives. ${ }^{41-43}$

Because of the potentially devastating impact of a false positive drug screen, it is essential for the MRO to be an authority on the pitfalls of urine drug tests. It is beyond the scope of this paper to give a comprehensive description of all problems encountered with testing; however, a few common predicaments and interesting scenarios are worth mentioning. There has been controversy as to whether passive smoke can produce positive screens for THC (marijuana metabolite) or benzoylecgonine (cocaine metabolite). The current body of data support that passive inhalation under normal, realistic conditions cannot give false positive screens for THC or cocaine ${ }^{44}$ However, false positive results have been reported for opiates with ingestion of large amounts of poppy, and for cocaine with ingestion of herbal cocoa tea, hence the importance of taking a history. ${ }^{45}$ The monoamineoxidase inhibitor selegiline, an anti-parkinsonian medication, can cause false positive screens for amphetamines. Likewise, Vicks Nasal Inhalers can cause a false positive screen for amphetamines. A knowledgeable MRO would order further resolution of the isomers, knowing that the $\mathrm{L}$ isomer in the urine is consistent with the use of Vicks, while the D isomer is consistent with amphetamines of abuse. ${ }^{45}$ The MRO may be faced with positive results from a subject self-medicating with a relative's pain medicine for an injury, and may deem the patient as negative if the history is confirmed and proper prescriptions are produced. Likewise, a patient may be drug positive from several tablets dispensed from an emergency department without a prescription. This would require the MRO to reach the treating physician for confirmation that the subject's test was in fact falsely positive for drugs. These are just a few simple circumstances which illustrate the necessity of medical review in any employee drug testing programme.

In the Samaritan Health Services study, alcohol accounted for only six $(3 \%)$ of the positive tests in the whole study period. It seems ironic that we have invested such extensive resources in screening for illegal substances when a potentially greater cause of workplace impairment may be associated with alcohol, a substance that is seldom tested for, and is legal. Even though alcohol may not be a standard substance in pre-employment drug panels in the health care industry, it is in some industries such as transportation. Samaritan Health Services considered alcohol a substance that could disqualify employment. Since a prospective employee had 24 hours notification prior to testing, it was felt that anyone who tested positive could be suspected of greater than social use of alcohol and was not fit to start work. It was not mentioned whether the MRO investigation of alcohol positive employees inquired about use of alcohol containing mouthwash or cough syrup.

\section{Does pre-employment testing deter drug abuse?}

In a 1994 article in the American Journal of Drug and Alcohol Abuse, Lange et al examined the drug use patterns of the applicants for jobs at The Johns Hopkins Hospital before and after a formal pre-employment urine drug testing programme was in place. ${ }^{46}$ During identical two month periods in 1989 and 1991, all prospective hospital employees were tested for drugs. Subjects were given two weeks notice prior to testing. Specimens were screened for amphetamines, barbiturates, benzodiazepines, cocaine, marijuana, opiates, phencyclidine, and methadone. University employees, such as medical staff and house officers, were not included in the study. In 1989, the institution's formal drug testing policy was solely "for cause" testing based on the pre-employment physical, and there was no medical review of positive results. During the study period, however, all applicants were tested, not just the "for cause" individuals. The test results of the study population did not influence whether or not the applicant was hired in 1989, unless the applicant was being tested "for cause" outside of the study. By 1991, a programme of preemployment urine drug testing was in place with medical review of positive results, so the 1991 cohort could be penalised for positive pre-employment screens.

Of the 593 specimens in 1989, 10.8\% were positive for one or more drugs. Presumably, this rate would have been even higher if the seven walkouts had provided specimens or if the 18 adulterated urine samples were repeated and included in the study. However, since there was no medical review in 1989 some of the positive tests may have been unrecognised false positives. Fifty five per cent of the positives were marijuana. In 1991 only $5.8 \%$ of the 365 urine samples tested positive (3.8\% were "true" positives after medical review), and there were no walk-outs. Twenty eight per cent of the positive screens were marijuana. Since the most drastic reductions in positive drug tests from 1989 to 1991 were for cocaine and marijuana, Lange et al believed that implementation of a formal pre-employment drug testing programme acted as a deterrent that discouraged drug users from initiating the application process. This may not be the sole explanation for fewer positive tests, however. Drug users may still have applied, but since they were given notice they were prepared to pass one-time tests by temporarily abstaining, water loading, or ingesting remedies in an effort to conceal use. Furthermore, the decreased rate of positive tests could also be explained in part by less drug use in that community in 1991, changing demographics within the applicant pool, and the use of medical review in 1991 but not 1989. Therefore, it remains unclear whether the deterring presence of a pre-employment drug testing programme was the main factor that led to fewer positive tests in 1991.

Lange et al also noticed the lack of sensitivity of "for cause" testing. Of the 64 employees positive for one or more drugs in 1989, only 24 aroused enough suspicion at the pre-employment physical examination from examiners to be tested "for cause". That means that a selective "for cause" policy of preemployment drug testing missed 40 applicants in a two month period that would have tested positive for drugs if all prospective employees were screened.

\section{CONCLUSIONS}

These studies have provided insight into the evolution of the current testing process for pre-employment urine drug screening of health care workers, at least in the United States. However, the topics of drug abuse by health care workers and patient safety are international issues. There is a conspicuous lack of published results of employee drug testing from hospitals outside the USA. The published experience, attitudes, and testing policies and strategies in other health care systems would be a welcome addition to the literature.

The logical next question is: what has over a decade of preemployment urine testing achieved? In order to answer this question, we need a better understanding of what the goals of drug screening really are. Explicit policies are the foundations of any testing programme, and must include clear, written statements of goals, measurable objectives, and delineation of operating procedures.$^{47}$ However, an analysis of the substance abuse policies at 30 teaching institutions found that policies were poorly formalised. Policies were vague with respect to which drugs were covered, procedural details, implementation of policy guidelines, and confidentiality. Moreover, policies seemed designed to ward off potential legal or bureaucratic problems rather than to set forth 
guidelines for employee or supervisory action. The authors suggested that such widespread ambiguity could be strategic to avoid conflict. ${ }^{23}$

Therefore, we first must figure out why we are testing in order to determine the best way to test. The most frequently cited reasons for testing are safety concerns and the DrugFree Workplace Act of $1988 .^{23}$ Other reasons to test are to detect and prevent substance abuse, improve work environment and morale, save money that would be lost from drug related expenses, and ethical reasons.

It has not yet been shown that pre-employment drug testing of health care workers has improved safety. The information needed, however, is readily attainable. Many goals of drug testing programmes could be evaluated by surveys and statistical review. Surveys targeting employee attitudes could be designed to determine if drug testing programmes indeed deter substance abuse by health care workers. Other surveys may determine whether a drug testing programme facilitates access to treatment resources by questioning those referred for treatment as a result of a positive test or those who voluntarily sought help in anticipation of testing positive. Whether drug testing makes employees feel safer at work or positively affects employee morale can also be evaluated by questionnaires. A potential wealth of information is available in employee health databases regarding drug screen results at institutions that have been testing for years. Statistics on absenteeism, turnover, accidents, injuries, and disciplinary actions could be analysed to determine whether drug testing programmes have had positive effects on these problems. Coordination of such statistics with these surveys and drug screen results may elucidate the efficacy of testing. If such efforts can show significant improvements in patient and workplace safety, then the continuation of such testing may justify the invasion of privacy such testing imposes.

If the purpose is for the employers to save money by reducing accidents, turnover, absenteeism, and the hiring of impaired employees, then each institution would have to perform its own cost effectiveness analysis. The cost of implementing such a testing programme can be accurately estimated and has been done for other industries. ${ }^{48}$ The exact dollar values are beyond the scope of this paper. There would be many factors that would have to be considered beyond simple laboratory and personnel expenses. Whether such a drug testing programme saves money overall depends on both the prevalence of drug use in the population screened and the costs related to adverse outcomes, such as accidents. ${ }^{49}$ The cost effectiveness of such programmes has been shown to be quite sensitive to small variations in the cost per urine sample charged by the laboratory..$^{48}$ Another important factor to consider would be the costs of a positive test, which would be either related to rehabilitation or hiring and training new employees, depending on the institution's policy.

It does seem that pre-employment drug screening of health care workers has achieved the goal of satisfying legal, public, and bureaucratic pressures. Pre-employment and "for cause" testing satisfy AHA recommendations and meet the least legal and employee resistance, while creating an illusion to the public that hospitals are drug free.

Ethically, however, systems that favour pre-employment and "for cause" testing fall short because they knowingly let drug abusers into the hospital work force. It has been shown that "for cause" testing is not sensitive in detecting substance abuse. ${ }^{46}$ Pre-employment testing encourages employees to simply pass a one time only test and will only detect the uninformed, forgetful, or most severely addicted individuals. One negative test certainly does not rule out substance abuse, nor can one positive result diagnose addiction, abuse, intoxication, or impairment. Moreover, this review and other literature suggest that pre-employment testing strategies are not applied uniformly to include all physicians at an institution. ${ }^{5}$ Random testing would fulfil the ethical duties to detect substance abuse in health care institutions and eliminate the double standards and stigmata of "for cause" and pre-employment testing.

If a goal of pre-employment drug testing is detection of illicit substance use, clearly such testing has not achieved its purpose. A survey of 342 anonymous physicians revealed that one third had used drugs in the previous year, and 9.5\% were regular users (at least once a month). Moreover, due to the nature of the survey questions, these figures were likely subject to reporting bias, ${ }^{13}$ making the true usage rates even higher. In the studies we have reviewed here, the majority of detection rates were well below this figure when a strategy of pre-employment testing was used. The disparity between this estimate and those of the studies reviewed here suggests that many regular and casual drug users are not detected by preemployment urine drug testing. Likewise, policies that rely on "for cause" testing have been proven to miss too many cases of illicit substance use. ${ }^{46}$ Moreover, the substances of abuse have evolved over the years. Substances like GHB (gamma hydroxybutyrate) and Ecstasy are more prevalent, and phencyclidine and barbiturates are less commonly abused. It is unlikely that screening panels have evolved to keep up with the changing patterns of substance abuse. Therefore, it is likely that most of the drug use by health care workers remains undetected.

Changes in testing strategy would likely improve detection. A less expensive and legally acceptable possibility may be to eliminate advance notice of pre-employment drug tests. Advance notice simply prepares drug abusers to pass the tests designed to detect them. However, a programme which truly focuses on drug detection would require a switch to random drug testing, which would be more expensive due to the need for a greater number of individual tests in order to optimise detection rates. In addition to the reluctance of hospital administrations to finance random testing, this system has greater potential to meet resistance from courts and labour organisations. However, a well conceived random drug testing programme that focuses on the public's interest while being sensitive to individual employee rights should be legally acceptable. ${ }^{5}$ While emphasising the duty to provide the best possible patient care and assuring safety from drug abusers, the policy would have to be announced to employees publicly and in writing, providing notice. There would have to be safeguards ensuring confidentiality, uniform application to all employees, and a responsible means for dealing with employees who test positive. If we are going to continue to test at all, we should do it fairly, properly, and for the right reasons.

Perhaps, the best testing strategy would not involve urine screening at all. The evolution of the science of drug testing has reached a point that urine may no longer be the best specimen to test. Urine tests for the most part can only confirm ingestion within the prior 72 hours. Hair testing can extend the window of detection from a few days to months, and can confirm abstinence in prior abusers. ${ }^{50}$ Saliva testing may also be promising because saliva is easy to collect and difficult to adulterate. ${ }^{51}$

Evidence based assessments of whether pharmacological substances impair healthcare provider work performance are still warranted. Pharmacologically active substances beyond identified drugs of abuse are known, but it is not clear which, if any substances, impact patient safety. Further, circadian disruption and exhaustion must be assessed as potential contributors to medical errors since overwork and night shifts may prompt stimulant use. The impact of substance use on 
patient safety is admittedly complex, but we must obtain further insight, especially as we devote our attention to achieving higher levels of patient safety.

\section{ACKNOWLEDGEMENTS}

We are indebted to Dr James Adams for his critical reviews and thoughtful comments.

\section{Authors' affiliations}

M R Levine, Division of Emergency Medicine, Department of Medicine, Northwestern Memorial Hospital, Feinberg Medical School,

Northwestern University, Chicago, Illinois, USA

W P Rennie, Emergency Medicine, Department of Emergency Medicine, Long Island Jewish Medical Center, Albert Einstein College of Medicine, New Hyde Park, New York, USA

\section{REFERENCES}

1 Ray O. Drugs, society, and human behaviour, 2nd edn. St Louis, MI: CV Mosby, 1978:129.

2 Bray RM, Marsden ME, Rachal JV, et al. "Drugs in the military workplace: results of the 1988 worldwide survey." Gust SW, et al, eds. Drugs in the workplace: research and evaluation data, Volume II. NIDA Monograph Series No.100 Washington, DC: NIDA, 1990:25-44

3 Reagan R. Executive order 12564. Federal Register, 17 September 1986, vol. 51, no. 180 .

4 Peat MA. Financial viability of screening for drugs of abuse. Clin Chem 1995:41:805-8.

5 Fenton JW, Kinard JL. A study of substance abuse testing in patient care facilities. Health Care Manage Rev 1993;18:87-95.

6 Brice J. Confronting drug abuse on the job. Healthcare Forum J JanFeb 1990:25-9.

7 Fonn M. Limiting access to drugs. Journalen Sykepleien 1993;81:24

8 Kelly M, Mynatt S. Addiction among nurses: does the health care industry compound the problem? Health Care Manage Rev 1990;14:35-42.

9 Firth-Cozens J. Emotional distress in junior house officers. Br Med J (Clin Res Ed) 1987:295:533-6.

10 Koran LM, Litt IF. House staff well-being. Western J Med 1988;148:97-101.

11 Plant ML, Plant MA, Foster J. Stress, alcohol, and tobacco use amongst nurses: a Scottish study. J Adv Nursing 1992;17:1057-67.

12 Brewster JM. Prevalence of alcohol and other drug problems among physicians. JAMA 1986;255:1913-20.

13 McAuliffe WE, Rohman M, Santangelo S, et al. Psychoactive drug use among practicing physicians and medical students. N Engl J Med 1986;315:805-10.

14 Kopstein A, Gfroerer J. Drug use patterns and demographics of employed drug users: data from the 1988 National Household Survey on Drug Abuse. Drugs in the workplace: research and evaluation data. Vol. II. NIDA Monograph Series, No.100. Rockville, MD: National Institute on Drug Abuse, 1991:11-24.

15 Lachman VD. Why we must take care of our own. Nursing April 1986;16:41.

16 Maddux JF, Hoppe SK, Costello RM. Psychoactive substance use among medical students. Am J Psychiatry 1986;143:187-91.

17 Colford J, McPhee S. The raveled sleeve of care: managing the stresses of residency training. JAMA 1989;261:889-93.

18 Tanner J, Kinard J, Cappel S, et al. Substance abuse and mandatory drug testing in health care institutions. Health Care Manage Rev 1988;13:33-42

19 Nemes J. Hospitals investigate suspected drug abuse. Mod Healthcare September 1989;29:34-5.

20 Cronin-Stubbbs D, Schaffner JW. Professional impairment: strategies for managing the troubled nurse. Nurs Adm Q 1985;9(3):44-54.

21 Fiesta J. The impaired nurse: who is liable? Nurs Manage October 1990;20:22
22 LaGodna GE, Hendrix MJ. Impaired nurses: a cost analysis. J Nurs Admin 1989;19(9):13-18.

23 Montoya ID, Carlson JW, Richard AJ. An analysis of drug abuse policies in teaching hospitals. J Behav Health Serv Res 1999;26(1):28-38.

24 American Hospital Association. Substance abuse policies for health care institutions. Chicago, IL: Management Advisory Human Resources, American Hospital Association, 1992.

25 Normand J, Salyards SD, Mahoney JJ. An evaluation of preemployment drug testing. J Appl Psychol 1990;75:629-39.

26 Zwerling C, Ryan J, Orav EJ. The efficacy of preemployment drug screening for marijuana and cocaine in predicting employment outcome. JAMA 1990;264:2639-43.

27 Lundberg GD. Urine drug screening: chemical McCarthyism. N Engl J Med 1972;287:723-4.

28 Rothstein MA. Preemployment drug screening may violate the ADA. J Occup Med 1993;35:554.

29 Moreland J. Types of drug-testing programmes in the workplace. Bull Narc 1993:45(2):83-113.

30 National Treasury Employees Union vs. Von Raab, 86-1879. Washington, DC: US Supreme Court, 21 March 1989.

31 Railway Labor Executives Association v. Skinner, 871555. Washington, DC: United States Supreme Court, 21 March 1989.

32 Rehabilitation Act of 1973. Public law 93-112. Washington, DC, 26 September 1973.

33 Walsh JM, Trumble J. The politics of drug testing. In: Coombs R, West $\amalg$, eds. Drug testing: issues and options. New York: Oxford University Press, 1991.

34 Smith R. Practicing 'zero tolerance'. Regulatory agencies should require preemployment and random drug tests at hospitals. Mod Healthc 1999;29(22): 27.

35 Lewy RL. Preemployment qualitative urine toxicology screening. J Occup Med 1983;25:579-80.

36 Lewy RL. Preemployment drug testing of housestaff physicians. NYS J Med October 1988:553-4

37 Lewy RM. Pre-employment drug testing of housestaff physicians at a large urban hospital. Acad Med 1991;66:618-19.

38 Smith DA, Hanbury R. Preemployment drug screening in a large metropolitan medical center: a one-month trial. J Gen Intern Med 1991;6(6):558-60.

39 Parish DC. Relation of the pre-employment drug testing result to employment status: a one-year follow-up. J Gen Intern Med Jan-Feb 1989;4:44-7.

40 Moore AB, Swafford LE. Preemployment urine substance screening. One-year experience of a large hospital system. J Occup Med 1993;35:71-4.

41 Osterloh JD, Becker CE. Chemical dependency and drug testing in the workplace. West J Med 1990;152:506-13.

42 Clark HW. The role of physicians as medical review officers in workplace drug testing programs. In pursuit of the last nanogram. West J Med 1990;152:514-24.

43 Vogl WF, Bush DM. Medical review officer manual for federal workplace drug testing programs. DHHS Publication No. (SMA) 97-3164, 1997.

44 ElSohly MA, Jones AB. Drug testing in the workplace: could a positive test for one of the mandated drugs be for reasons other than illicit use of the drug? J Anal Tox 1995; 19:450-8.

45 McBay AJ. Drug-analysis technology-piffalls and problems of drug testing. Clin Chem 1987;33(11B):33B-40B.

46 Lange WR, Cabanilla BR, Moler G, et al. Preemployment drug screening at The Johns Hopkins Hospital, 1989 and 1991. Am J Drug Alcohol Abuse 1994;20:35-46.

47 Hanson M. Overview on drug and alcohol testing in the workplace. Bull Narc 1993;45(2):3-44.

48 Zwerling C, Ryan J, Orav J. Costs and benefits of preemployment drug screening. JAMA 1992;267:91-3.

49 Zwerling C, Ryan J. Preemployment drug screening-the epidemiologic issues. J Occup Med 1992;34:595-9.

50 Hersch RK, McPherson TL, Cook RF. Substance use in the construction industry: a comparison of assessment methods. Subst Use Misuse 2002;37:1331-58.

51 Reynolds LA. What you should know... about on-site saliva drug and alcohol testing. Occup Health Saf 2001;70(9):188-90. 